Article

\title{
Technical and Economic Criteria to Select Pavement Surfaces of Port Handling Plants
}

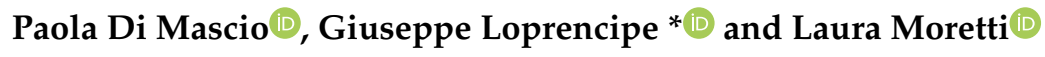 \\ Department of Civil, Construction and Environmental Engineering, Sapienza University of Rome, 00184 Rome, \\ Italy; paola.dimascio@uniroma1.it (P.D.M.); laura.moretti@uniroma1.it (L.M.) \\ * Correspondence: giuseppe.loprencipe@uniroma1.it; Tel.: +39-06-4458-5112
}

Received: 31 December 2018; Accepted: 14 February 2019; Published: 18 February 2019

check for updates

\begin{abstract}
A port is an intermodal system in which many logistics activities requiring properly constructed areas occur. The large extension of these areas poses a major problem in choosing materials with technical and economic implications. Choice and design of pavements are directly related to the port handling systems and procedures for the disposal of the cargo units. The paper presents the design and verification procedures for three equivalent pavements for a handling pavement in an Italian medium-sized port trafficked by reach stackers moving containers. An asphalt pavement, a concrete pavement, and a concrete block pavement have been considered during the 20 -year service life. Empirical and analytical methods have been adopted to design and verify the pavements. The structures have been examined in terms of economic concerns during the overall service life, considering both construction and maintenance costs, in order to determine the most cost-effective option. The results demonstrate the inappropriateness of asphalt pavement, in the examined case, from a construction costs point of view. Furthermore, the overall discounted costs show an inversion of convenience between block concrete pavement and cast in situ concrete: the latter is the cheaper solution. The proposed methodology can balance often conflicting objectives in matters of durability and funds management, providing answers to a complex topic.
\end{abstract}

Keywords: container terminal; heavy load pavement; reach stackers; port pavement surfaces; costs evaluation

\section{Introduction}

Selection criteria of port pavements constitute a fundamental aspect, which has a strong impact on both functional operation and economic investment of a port during its whole service life [1]. Port activities imply several traffic demands, which are very different from each other and include loading docks, handling, and storage of goods, and the circulation of light, heavy, and very heavy vehicles [2].

The design of pavements plays a crucial role because their construction and maintenance have a cost: according to Meletiou and Knapton [3], pavement costs represent up to $25 \%$ of the total cost of construction of a port. Therefore, port pavement management plays a crucial role from design, to construction, to rehabilitation [4] in order to optimize the available resources according to the life cycle cost analysis (LCCA) approach [5].

In port areas, different types of vehicles are moving and working: the system of operational, productive, and economic activities is complex, and it requires careful design choice of pavements according to their use. Some functional areas can be distinguished in:

- Sidewalks and pedestrian areas: These areas should guarantee functional requirements [6-8], ensuring regularity and user safety under any operating condition (e.g., meteorological conditions). 
- Access and internal roads: It consists of roads affected by promiscuous traffic, both light and heavy. As regards the design loads and solutions, it is possible to adopt the types listed in the literature for ordinary roads [9].

- Parking lots for light vehicles: These areas are subjected to road vehicles loads. The solar radiation and frequently long duration of parking could cause permanent deformations on thermosensible pavements.

- Parking lots for heavy vehicles: Heavy vehicles stand in these areas waiting for moving goods or processing administrative practices or resting for a period. The zones are usually loaded for enough time to trigger viscous phenomena and therefore permanent pavement deformations (i.e., rutting).

- Cargo handling: Two vehicle types are of interest for this area: unconstrained guide (e.g., lift trucks, mobile cranes rubber-tired carriers and wheeled tractors) or constrained transport systems (e.g., overhead traveling cranes). Static loads induced during handling storage units are comparable to ones induced by airplanes or heavy road vehicles. Moreover, dynamic actions of these vehicles cannot be overlooked: Appropriate coefficients are usually used to increase the static loads [10];

- Containers storage areas: In order to optimize the available space, often containers are arranged in parallel rows up to three or four superposed planes: The load transmitted to the pavement is up to $1000 \mathrm{kN}$ on a $61 \mathrm{~cm}$-side square surface [11].

Port pavements can be classified into four main types: flexible, semi-rigid, rigid, and block pavements [3].

- Flexible pavements are generally constituted by four layers arranged in the depth from the surface:

- Wearing and binder layers composed of asphalt concrete, which are subjected to high shear and flexural stresses which cause rutting and cracking;

○ base course composed of bituminous concrete or bitumen-bound granular if high stresses are expected, otherwise granular mixtures are commonly used;

- subbase composed of granular course, which is usually only subjected to vertical tensions and it has a function of loads distribution on the subgrade;

- subgrade, the upper layer of the natural soil which may be the undisturbed local material.

- Semi-rigid pavements are very similar to flexible pavements, but they have a cement-bound base layer. Semi-rigid pavements are used in presence of very heavy traffic (to be considered both as number of repetitions and entity of loads). Both flexible and semi-rigid pavements have a design period 15-20 years long.

- Rigid pavements are composed of a concrete slab laid on one or two subbase layers composed of cement-bound material or granular mix. Concrete slabs often have a square pattern for better load spreading. If any longitudinal or transverse steel reinforcement is present, it controls the widening cracks due to concrete thermal deformations.

- Concrete block pavements are typically composed of pre-formed modular pavers on a bedding layer, a base course, and a subbase layer. Used for the first time in the northern European ports, they are now used all over the world. The experience gained over many years shows that as the side length grows, so too does the stress-strain and more block thickness is required. Both rigid and concrete block pavements have a service life not less than 20-40 years.

Semi-rigid and flexible pavements are generally unsuitable for parking areas reserved to heavy vehicles (Table 1): Continuous loads trigger creep deformations of asphalt [12]. 
Table 1. Suitability of pavements for different areas considering cost-effectiveness and performance.

\begin{tabular}{|c|c|c|c|}
\hline \multirow{2}{*}{ Type of Area } & \multicolumn{3}{|c|}{ Type of Pavement } \\
\hline & Semi-Rigid and Flexible & Concrete & Modular Pavers \\
\hline \multirow{2}{*}{$\begin{array}{l}\text { Access and internal } \\
\text { roads }\end{array}$} & $\odot$ & $\odot$ & $\odot$ \\
\hline & Suitable for light vehicles & LCCA needs & LCCA needs \\
\hline \multirow{2}{*}{$\begin{array}{l}\text { Parking lots for heavy } \\
\text { vehicles }\end{array}$} & $\ddot{\theta}$ & 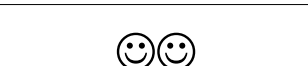 & $(\ddot{)}$ \\
\hline & $\begin{array}{l}\text { Avoid in presence of long } \\
\text { period parking and oil spill }\end{array}$ & Recommended solution & Reasonable solution \\
\hline \multirow[b]{2}{*}{ Cargo handling } & $\ddot{\theta}$ & 尺: & $(\dot{)}$ \\
\hline & $\begin{array}{l}\text { suitable only for guided public } \\
\text { transport }\end{array}$ & reasonable solution & $\begin{array}{c}\text { suitable only for } \\
\text { low-tangential stresses }\end{array}$ \\
\hline \multirow{2}{*}{ Containers storage areas } & $\ddot{\theta}$ & (;) & $\odot \odot$ \\
\hline & avoid if possible & good solution & recommended solution \\
\hline \multirow[b]{2}{*}{ Light vehicle parking } & & (;) & (ن) \\
\hline & reasonable solution & $\begin{array}{l}\text { suggested permeable } \\
\text { concrete }\end{array}$ & $\begin{array}{l}\text { suggested vegetative and } \\
\text { permeable blocks }\end{array}$ \\
\hline \multirow[b]{2}{*}{ Pedestrian } & (ن) & $\stackrel{\circ}{\circ}$ & $\curvearrowright$ \\
\hline & $\begin{array}{l}\text { even dirt road with } \\
\text { anti-dusting bituminous layer }\end{array}$ & LCCA needs & reasonable solution \\
\hline
\end{tabular}

Indeed, this material varies its stiffness with temperature, and it deforms continuously during construction, it permits the use of the pavement a few hours after layering, and during exercise, and the resulting pavement can be without joints. When loads vary rapidly (i.e., moving vehicles), asphalt behaves as an elastic solid. However, the rheological characteristics of bituminous materials lead to rutting, and tangential stresses induced by vehicles may alter functional performances of pavements. Conversely, semi-rigid and flexible pavements are maintained easily and quickly.

Unlike bituminous pavements, the mechanical and physical properties of concrete pavements do not suffer from rutting. The construction costs of rigid pavements are generally more expensive than asphalt pavements, especially if a high level of surface regularity is required [13]. However, they are suitable for high shear stresses, or concentrated vertical loads, or areas subjected to fuel spillage, which can result in structural or functional distresses on asphalt pavements [14,15]. Maintenance management of a rigid pavement is less frequent and expensive compared to a flexible pavement.

Block pavements are appropriate for prolonged stationing areas due to their resistance to concentrated loads [16]. Experience gained on this topic shows that the larger the side lengths is, the higher stress concentrations are: In order to limit stresses, blocks used for heavy loaded port pavement have a roundish shape. The success of this solution depends on the regularity and load bearing of the subgrade or laying surface.

This paper presents the design and verification of three pavements for a handling port area trafficked by a reach stacker. The authors considered this vehicle because this type of port traffic is growing as a consequence of growing container use [17]. For example, in the last decade in Italian ports more than $30 \%$ of moved cargo was Twenty-foot Equivalent Unit (TEU).

An asphalt pavement, a concrete cast in situ pavement, and a concrete block pavement have been designed according to empirical methods in the available literature. For each structure typology, the obtained results have been compared to those obtained using analytical methods in order to calculate stresses and strains induced by traffic loads, and to design correctly the pavements. Finally, the results have been economically compared to find the most cost-effective solution. As observed, the main contribution of this work with respect to existing studies is a new methodology to identify the best pavement solution by the combined evaluation of economic and technical criteria. 


\section{Materials and Methods}

In the design process of port pavement several methods and procedure could be adopted $[18,19]$. They could be divided into two categories: empirical and rational methods. The first methods are based on experimental data about the behavior of existing pavements [20-23]. Using the results, useful diagrams can be compiled that define the layers' thickness as a function of few parameters (e.g., the bearing capacity of the subgrade and the number of load repetitions of a reference axle).

For more in-depth structural analysis, rational methods should be adopted, such as the elastic multilayer or the finite element ones [24]. They enable the calculation of the stress-strain state induced by a load and to verify the results obtained from empirical methods.

A third design approach should be considered. It consists of catalogs, already existing in some countries [25], which give pre-established solutions. Therefore, they are turn-key tools, as the empirical methods. However, the proposed solutions derive from theoretical methods: They are more general than those obtained from empirical methods.

The input data used to design the pavements were compliant with average values of materials properties [26] and typical weather conditions [27] in Northern Italy.

The subgrade bearing capacity was defined through the resilient modulus of the soil (SM), and it was supposed to equal to $50 \mathrm{MPa}$, which corresponds to a California bearing ratio (CBR) equal to $5 \%$ [28].

The expected demand of traffic was equal to 30,000 passes/year during 20-year service life. The design vehicle was a reach stacker, as represented in Figure 1; Table 2 lists its characteristics.

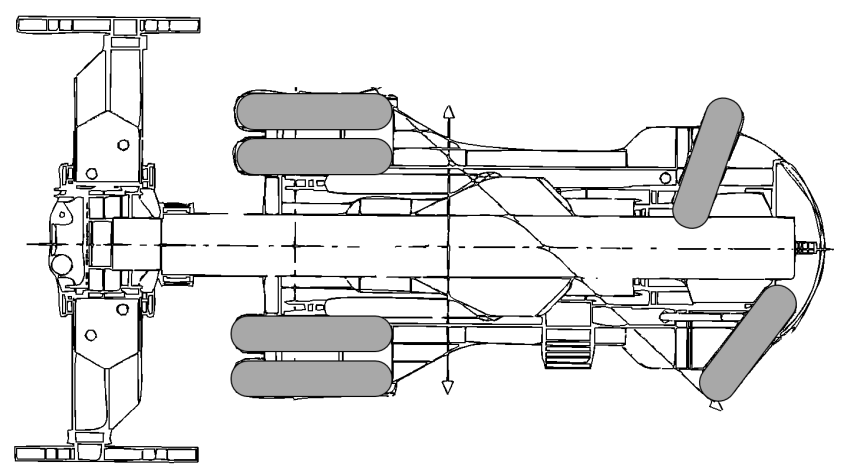

Figure 1. Plan view of a reach stacker.

Table 2. Characteristics of design of a reach stacker.

\begin{tabular}{cccc}
\hline Characteristic & Symbol & Value & Units \\
\hline Unladen weight & $\mathrm{UW}$ & 65 & $\mathrm{Mg}$ \\
Lifting capacity & $\mathrm{LC}$ & 45 & $\mathrm{Mg}$ \\
Service weight & $\mathrm{SW}$ & 110 & $\mathrm{Mg}$ \\
Number of wheels, front/rear & $\mathrm{NW}, \mathrm{f} / \mathrm{r}$ & $4 / 2$ & - \\
Wheelbase & $\mathrm{Wb}$ & 5750 & $\mathrm{~mm}$ \\
Track width & $\mathrm{TW}$ & 3000 & $\mathrm{~mm}$ \\
Center-to-center spacing between dual tires & SDT & 800 & $\mathrm{~mm}$ \\
Distance between the two inner front axle & $\mathrm{DWC}$ & 2400 & $\mathrm{~mm}$ \\
wheel centers & $\mathrm{DLC}$ & 2700 & $\mathrm{~mm}$ \\
Distance of load center from front axle & $p$ & 1 & $\mathrm{MPa}$ \\
Tire pressure, front/rear & &
\end{tabular}

According to the geometrical characteristics listed in Table 2, the maximum weight of the front axle $\mathrm{SW}_{\mathrm{f}}$, which has dual wheels, was Equation (1):

$$
\mathrm{SW}_{\mathrm{f}}=\frac{\mathrm{SW}}{2}+\mathrm{LC} \frac{\mathrm{Wb}+\mathrm{DLC}}{\mathrm{Wb}}=98.6 \mathrm{Mg}
$$


Flexible pavement has been designed according to the method proposed by the Asphalt Institute [22] for heavy wheel loads and implemented in a computerized method for pavement thickness design [23]. The method gives the overall thickness of bituminous layers $T_{A}$ required by an equivalent single wheel load (ESWL). $T_{A}$ depends on the wheel contact radius ( $a$ ) and the tire-ground contact pressure $(p)$. In presence of dual-wheel load axle, the problem is solved by mean a graphical solution that compares the curves of allowable single wheel loads (ASWL) with the curve of ESWL. Fatigue and rutting analyses have been performed to verify the designed pavement.

Jointed plain cast in situ concrete slabs concrete pavement has been designed according to the procedure proposed by the Portland Cement Association (PCA) for industrial pavements [29]. Slabs thickness has been verified according to the Westergaard [30] and the Bradbury [31] theories in order to prevent fatigue rupture.

The block pavement has been designed according to the method proposed by Knapton [21] for heavy duty pavements for ports and other industries. The method considers the most loaded axle to design the pavement. For the considered reach stacker, the front axle is the critical one: Due to its geometry, the maximum tensile stress beneath a wheel loaded derives from the load on the wheel and the loads of nearby wheels. All four wheels contribute to the stress under the critical wheel, which is the inner front axle wheel.

For each designed pavement, an economic analysis of construction and maintenance costs was carried out. The construction costs were evaluated using the lists of road prices currently valid in Italy $[26,32]$. Strategies of maintenance plans were defined based on common practices available in the literature [33-35]. Maintenance costs were estimated according to an Italian roads price list [36] and to data recently used for similar studies [37]. The inflation and discount rates were assumed constant during the service life and equal to $1.5 \%$ and $0.4 \%$, respectively. These rates derived from the average values for the last 15 years in Italy and the economic forecast for the year 2050 [38-40].

\section{Pavement Design}

\subsection{Flexible Pavement}

The method proposed by the Asphalt Institute [22] gives ASWL curves to calculate $T_{A}$ needed for 10,000 and 100,000 yearly passes (Figure 2) and several values of SM when the yearly average daily temperature is not more than $13{ }^{\circ} \mathrm{C}$.

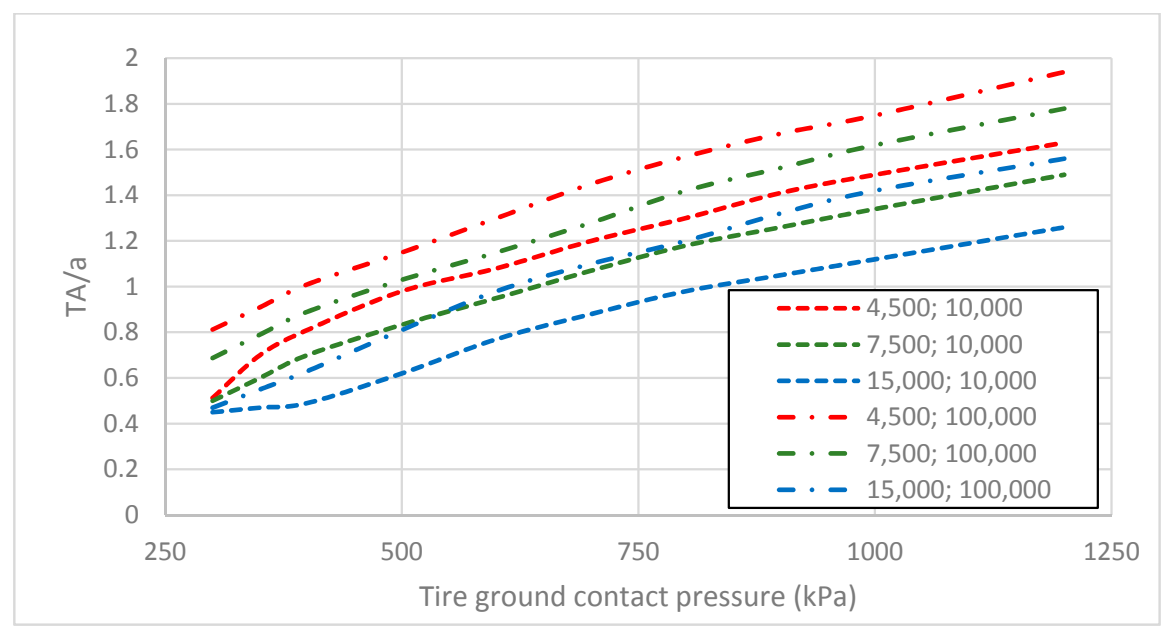

Figure 2. Design $T_{A}$ / $a$ values for the allowable single wheel loads (ASWL) curves. In the legend the first number refers to the SM value in psi; the second number refers to the overall number of passes.

In the examined case (i.e., SM equal to $7500 \mathrm{psi}$ and $p$ equal to $1000 \mathrm{kPa}$ ), $T_{A} / a$ was 1.4 for 10,000 passes and 1.6 for 100,000 passes. For ASWL ranging between the maximum design wheel load MDWL 
(Equation (2)) and 0.6.SW (i.e., $660 \mathrm{kN}$ ), $T_{A}$ values have been calculated. The ASWL curves for 10,000 and 100,000 yearly passes were drawn using the obtained data (Table 3 ).

$$
\mathrm{MDWL}=\frac{\mathrm{SW}_{\mathrm{f}}}{4}=250 \mathrm{kN}
$$

Table 3. Data to draw ASWL curves for 10,000 and 100,000 yearly passes.

\begin{tabular}{cccccc}
\hline \multirow{2}{*}{ ASWL (kN) } & \multirow{2}{*}{$(\mathbf{m})$} & \multicolumn{2}{c}{$N=\mathbf{1 0 , 0 0 0}$} & \multicolumn{2}{c}{$N=\mathbf{1 0 0 , 0 0 0}$} \\
\cline { 3 - 5 } & & $\boldsymbol{T}_{A} / \boldsymbol{a}$ & $\boldsymbol{T}_{\boldsymbol{A}}(\mathbf{m})$ & $\boldsymbol{T}_{A} / \boldsymbol{a}$ & $\boldsymbol{T}_{\boldsymbol{A}}(\mathbf{m})$ \\
\hline 250 & 0.282 & & 0.395 & & 0.451 \\
300 & 0.309 & & 0.433 & & 0.494 \\
350 & 0.334 & & 0.467 & & 0.534 \\
400 & 0.357 & & 0.500 & & 0.571 \\
450 & 0.378 & \multirow{2}{*}{1.4} & 0.530 & 1.6 & 0.606 \\
500 & 0.399 & & 0.559 & & 0.638 \\
550 & 0.418 & & 0.586 & & 0.669 \\
600 & 0.437 & & 0.612 & & 0.699 \\
660 & 0.458 & & 0.642 & & 0.733 \\
\hline
\end{tabular}

According to reference [22], the ESWL curve was obtained for $T_{A} / a$ varying from 1 to 4 (Figure 3) and dual-wheel loads (DWL). Indeed, using the load factors $L$ the ESWLs could be calculated according to Equation (3).

$$
\mathrm{ESWL}=\frac{\mathrm{DWL}}{L}
$$

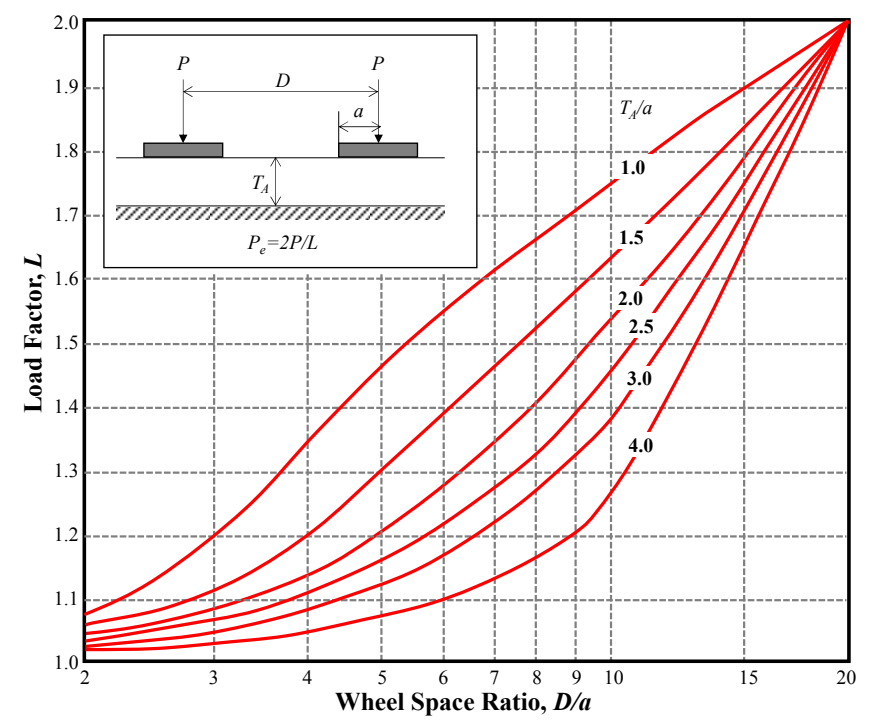

Figure 3. Dual-wheel load factors.

Table 4 lists data needed to draw the equivalent single wheel load (ESWL) curve. 
Table 4. Data to draw the ESWL curve.

\begin{tabular}{ccccc}
\hline $\boldsymbol{T}_{\boldsymbol{A}} / \boldsymbol{a}$ & $\boldsymbol{L}$ & $\mathbf{D W L}(\mathbf{k N})$ & EWSL $(\mathbf{k N})$ & $\boldsymbol{T}_{\boldsymbol{A}}(\mathbf{m})$ \\
\hline 1.0 & 1.17 & 250 & 427.35 & 0.282 \\
1.4 & 1.11 & 300 & 450.45 & 0.395 \\
1.6 & 1.09 & 350 & 458.72 & 0.451 \\
2.0 & 1.07 & 400 & 467.29 & 0.564 \\
2.5 & 1.055 & 450 & 473.93 & 0.705 \\
3.0 & 1.04 & 500 & 480.77 & 0.846 \\
4.0 & 1.03 & 550 & 485.44 & 1.128 \\
\hline
\end{tabular}

Finally, the curve of ASWL for 30,000 passes was calculated by linear interpolation between the obtained ASWL curves for 10,000 and 100,000 passes (Table 3). The intersection (Figure 4) between the 30,000 ASWL passes and the ESWL passes curves gives $T_{A}$ : The required thickness of asphalt pavement is $0.56 \mathrm{~m}$.

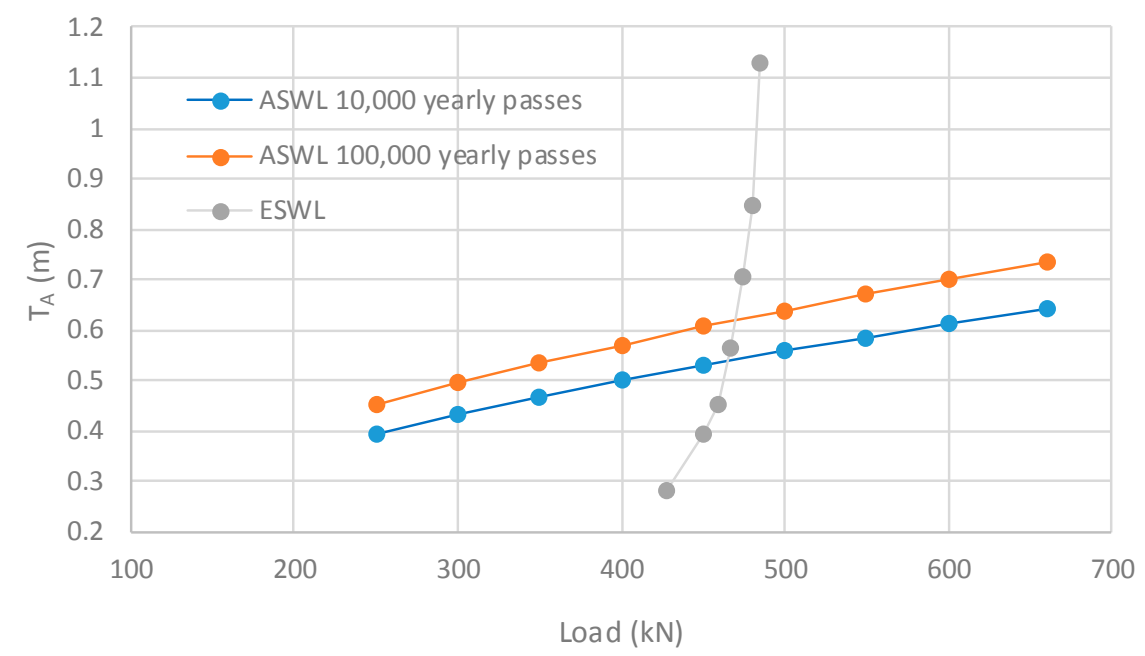

Figure 4. Graph for identification of $T_{A}$.

According to the obtained results, the flexible pavement is composed of the following:

- $8 \mathrm{~cm}$-thick asphalt concrete wearing course;

- $8 \mathrm{~cm}$-thick asphalt concrete binder course;

- $40 \mathrm{~cm}$-thick asphalt concrete base course.

Finally, the software BISAR 3.0 has been used. BISAR [41] is a tool to solve the multilayered structure of a pavement; its reliability is well recognized because as it has been used for a long time. Therefore, the horizontal tensile strain at the bottom of the base layer and the vertical compressive strain at the surface of the subgrade have been calculated with this software. These values enabled the following:

- The asphalt fatigue verification according to Equation (4):

$$
N=f_{1} \cdot\left(\varepsilon_{\mathbf{z}}\right)^{-f_{2}} \cdot E^{-f_{3}}
$$

where $N$ is the number of allowable load repetitions; $\varepsilon_{z}$ is the maximum induced horizontal strain; $E$ is the elastic modulus of the asphalt concrete; $f_{1}$ is a coefficient equal to $7.96 \times 10^{-2} ; f_{2}$ is a coefficient equal to $3.29 ; f_{3}$ is a coefficient equal to $8.54 \times 10^{-1}$. Three values of asphalt elastic modulus have been considered to take into account seasonal variability of mechanical performances of asphalt layers.

- The subgrade rutting verification according to Equation (5) [24]:

$$
N=f_{4} \cdot \varepsilon_{\mathrm{c}}-f_{5}
$$


where $\varepsilon_{\mathrm{c}}$ is the maximum induced vertical strain; $f_{4}$ is a coefficient equal to $1.365 \times 10^{-9} ; f_{5}$ is a coefficient equal to 4.477 .

Both verifications have been carried out according to the Miner's law (Equation (6)) [42].

$$
\sum_{i} \frac{n_{i}}{N_{i}} \leq 1
$$

where $n$ is the number of expected load repetitions during the service life.

Tables 5 and 6 list the results of fatigue and rutting verification, respectively. In this analysis, the authors considered a not-modified bitumen binder and the average mechanical properties of asphalt mixtures in Italy.

Table 5. Fatigue verification of asphalt layers.

\begin{tabular}{cccccc}
\hline Season & $\boldsymbol{E} \mathbf{( M P a )}$ & $\mathcal{E}_{\mathbf{z}}(-)$ & $\boldsymbol{N}$ & $\boldsymbol{n}$ & $n / \boldsymbol{N}$ \\
\hline Winter & 10,000 & $7.08 \times 10^{-5}$ & $7.22 \times 10^{9}$ & 150,000 & $2.08 \times 10^{-5}$ \\
Spring/Autumn & 7000 & $9.41 \times 10^{-5}$ & $3.84 \times 10^{9}$ & 300,000 & $7.81 \times 10^{-5}$ \\
Summer & 3000 & $1.46 \times 10^{-4}$ & $1.87 \times 10^{9}$ & 150,000 & $8.04 \times 10^{-5}$ \\
\hline$\sum n / N$ & - & - & - & - & $1.79 \times 10^{-4}$ \\
\hline
\end{tabular}

Table 6. Subgrade rutting verification-asphalt pavement.

\begin{tabular}{cccc}
\hline$\varepsilon_{\mathrm{c}}(-)$ & $N$ & $n$ & $n / N$ \\
\hline $1.46 \times 10^{-4}$ & $2.56 \times 10^{8}$ & 600,000 & $2.34 \times 10^{-2}$ \\
\hline
\end{tabular}

The designed flexible pavement has been verified.

\subsection{Rigid Pavement}

Input data for designing concrete slabs are listed in Table 7.

Table 7. Mechanical and physical characteristics of pavement materials.

\begin{tabular}{ccc}
\hline Characteristic & Value & Units \\
\hline Concrete flexural tensile strength at 90 days & 6 & $\mathrm{MPa}$ \\
Young's modulus of concrete & 45,000 & $\mathrm{MPa}$ \\
Poisson ratio & 0.15 & - \\
Allowable maximum tensile stress & 2.4 & $\mathrm{MPa}$ \\
Modulus of subgrade (or subbase) reaction & 0.21 & $\mathrm{MPa} / \mathrm{mm}$ \\
\hline
\end{tabular}

Given the number of repetitions during the service life, the design stress ratio (equal to the ratio between the critical applied flexural stress and the flexural stress of concrete) was equal to 0.40 according to the PCA procedure [29]. The design chart for dual-wheel loading gave a pavement composed of the following:

- $42 \mathrm{~cm}$-thick concrete slabs;

- $20 \mathrm{~cm}$-thick cement-bound subbase.

For the fatigue analysis, according to Westergaard [30], Equations (7) and (8) can be used to calculate the maximum tensile stresses at the bottom of the slab for a load at the interior or at the edge of the slab:

$$
\begin{gathered}
\sigma_{\mathrm{i}}=0.275 \cdot(1+v) \cdot \frac{P}{h^{2}}\left[4 \cdot \log _{10}\left(\frac{l}{b}\right)+1.069\right] \\
\sigma_{\mathrm{e}}=0.529 \cdot(1+0.54 \cdot v) \cdot \frac{P}{h^{2}}\left[4 \cdot \log _{10}\left(\frac{l}{b}\right)+0.359\right]
\end{gathered}
$$


where $\sigma_{\mathrm{i}}$ is the maximum tensile stress at the bottom of the slab due to loading at the interior; $\sigma_{\mathrm{e}}$ is the maximum tensile stress at the bottom of the slab due to loading at the edge; $P$ is the wheel load; $h$ is the slab thickness; $v$ is the Poisson's ratio of the concrete; $a$ is the radius of the wheel load; $b$ is the radius of the resisting section given by Equations (9) and (10):

$$
\begin{gathered}
b=\sqrt{1.6 \cdot a^{2}+h^{2}}-0.675 \cdot h i f a<1.724 \cdot h \\
b=a i f a \geq 1.724 \cdot h
\end{gathered}
$$

In the Equations (7) and (8), $l$ is the radius of relative stiffness given by Equation (11):

$$
l=\sqrt[4]{\frac{E \cdot h^{3}}{12 \cdot\left(1-v^{2}\right) \cdot k}}
$$

where $E$ is the Young's modulus of the concrete; $k$ is the sub-grade reaction modulus.

The Bradbury equations can be used to calculate the maximum tensile stress induced by the temperature at the center and the edge of the slab (Equations (12) and (13)) [31]:

$$
\begin{gathered}
\sigma_{\mathrm{wi}}=\frac{E \alpha \Delta t}{2}\left(C_{1}+v C_{2}\right) \\
\sigma_{\mathrm{we}}=\frac{E \alpha \Delta t}{2} \mathrm{C}
\end{gathered}
$$

where $\sigma_{\mathrm{wi}}$ is the maximum thermal stress at the interior position of the slab; $\sigma_{\mathrm{we}}$ is the maximum thermal stress at the edge of the slab; $\alpha$ is the coefficient of linear thermal expansion; $\Delta t$ is the temperature gradient between the bottom and top; $C, C_{1}$ are coefficients which depend on the length $L x$, the width $L y$, and the radius of relative stiffness $l$ of the slabs (in the direction under investigation) according to Figure $5 ; C_{2}$ is a coefficient which depends on the length $L x$, the width $L y$, and the radius of relative stiffness $l$ of the slabs (in the direction perpendicular to the investigated zone) according to Figure 5. Particularly, $C$ and $C_{1}$ coincide and derive from the ratio $L x / l ; C_{2}$ derives from the ratio $L y / l$.

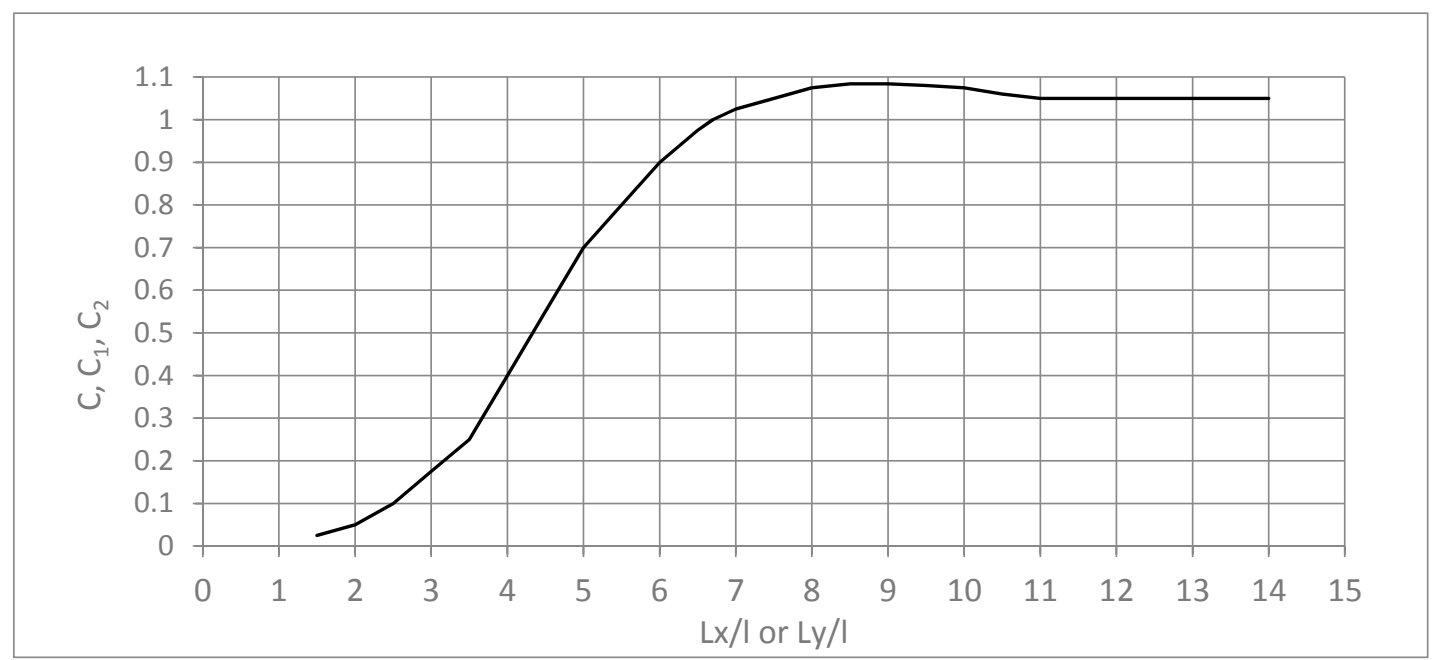

Figure 5. Bradbury's warping stress coefficients.

$5.50 \mathrm{~m}$-side square slabs with dowel and tie steel bars respectively at transverse and longitudinal joints have been designed because of the severe stress-strain conditions caused by cornering and braking of heavy loads. This geometrical and technical solution is the most common choice adopted in Italian ports. 
The fatigue verification has been carried out according to the Miner's law [42] (Equation (6)) and the PCA fatigue law [29] (Equation (14)):

$$
\frac{\sigma}{\mathrm{MR}}=0.9715-0.0824 \cdot \log N
$$

where $\sigma$ is the maximum tensile stress in the slab given by the superposition of traffic and thermal effects, MR is the concrete flexural tensile strength at 90 days.

The designed $42 \mathrm{~cm}$-thick slabs did not satisfy the fatigue verification: their thickness should be increased. Therefore, a rigid pavement composed of the following:

- $43 \mathrm{~cm}$-thick concrete slabs;

- $20 \mathrm{~cm}$-thick cement-bound base.

has been examined. It ensured the verification results in Table 8 .

Table 8. Mechanical and physical characteristics of pavement materials.

\begin{tabular}{cccc}
\hline$\sigma(\mathrm{MPa})$ & $\boldsymbol{N}$ & $n$ & $n / N$ \\
\hline 0.59 & $6.41 \times 10^{8}$ & 600,000 & $9.37 \times 10^{-4}$ \\
\hline
\end{tabular}

The designed rigid pavement has been verified.

\subsection{Block Pavement}

The method proposed by Knapton [21] uses the proximity factor $p_{f}$ to take into account the presence of wheels in close proximity. $p_{f}$ depends on the wheel spacing and the effective depth $e_{d}$ which is the theoretical depth of the slab (in mm) (Equation (15))

$$
e_{d}=300 \cdot \sqrt[3]{\frac{35,000}{\mathrm{CBR} \cdot 10}}
$$

In the examined case, $e_{d}$ is $2663 \mathrm{~mm}$. $p_{f}$ has been calculated for three distances (i.e., SDT, DWC, and DWC + SDT): each one represents the distance between the critical front wheel and the other three front wheels (Table 9).

Table 9. Values of proximity factors.

\begin{tabular}{ccc}
\hline Load & Wheel Spacing $(\mathbf{m m})$ & $p_{f}$ \\
\hline SDT & 800 & 0.80 \\
DWC & 2400 & 0.19 \\
DWC + SDT & 3200 & 0.07 \\
\hline
\end{tabular}

Therefore, the static overall load SL under the critical wheel was (Equation (16)):

$$
\mathrm{SL}=\mathrm{MDWL} \cdot\left(1+\sum_{i} p_{f, i}\right)=\mathrm{MDWL} \cdot(1+0.8+0.19+0.07)=507 \mathrm{kN}
$$

Moreover, the method [21] considers the effects of dynamic conditions due to cornering, accelerating, braking, and surface unevenness. For reach stackers, the dynamic factors $d_{f, i}$ that increase the static loads are listed in Table 10: 
Table 10. Dynamic factors.

\begin{tabular}{cc}
\hline Condition & $\boldsymbol{d}_{f, i}$ \\
\hline Braking & $30 \%$ \\
Cornering & $40 \%$ \\
Accelerating & $10 \%$ \\
Surface unevenness & $20 \%$ \\
\hline Total & $100 \%$ \\
\hline
\end{tabular}

The design dynamic load (DL) under the critical wheel was $1014 \mathrm{kN}$ (Equation (17)).

$$
\mathrm{DL}=\mathrm{SL} \cdot\left(1+\sum_{i} d_{f, i}\right)=1014 \mathrm{kN}
$$

Having 600,000 passes of DL throughout the design life, the required block pavement had the following characteristics:

- $80 \mathrm{~mm}$-thick concrete pavers with plan dimensions $200 \mathrm{~mm} \times 100 \mathrm{~mm}$;

- $30 \mathrm{~mm}$-thick bedding sand;

- $700 \mathrm{~mm}$-thick lean concrete base with characteristic compressive cube strength equal to $10 \mathrm{MPa}$;

- $150 \mathrm{~mm}$ crushed rock base material with a CBR equal to $80 \%$.

Fatigue verification of the base layer and rutting verification of the subgrade have been carried out calculating stresses and strains by mean the software BISAR [41].

Equations (5) and (6) can be used for verification of the granular base and subgrade rutting. The results are listed in Table 11.

Table 11. Rutting verification-block pavement.

\begin{tabular}{cccc}
\hline Layer & $\mathcal{E}_{\mathrm{C}}(-)$ & $\boldsymbol{n}$ & $\boldsymbol{n} / \boldsymbol{N}$ \\
\hline granular base & $0.215 \times 10^{-4}$ & 600,000 & $5.57 \times 10^{-7}$ \\
subgrade & $0.215 \times 10^{-5}$ & 600,000 & $9.30 \times 10^{-12}$ \\
\hline
\end{tabular}

Equation (18) [43] and Equation (6) can be used for the fatigue analysis of the cement-bound base course:

$$
N=10^{\left(25 \cdot \frac{\sigma_{\mathrm{R}}-\sigma_{\mathrm{N}}}{\sigma_{\mathrm{R}}}\right)}
$$

where $\sigma_{R}$ is the tensile strength of cement-bound base course (assumed equal to $0.1 \mathrm{MPa}$ ); $\sigma_{\mathrm{N}}$ is the maximum tensile stress. Table 12 lists the results.

Table 12. Fatigue analysis for cement-bound base course-block pavement.

\begin{tabular}{cccc}
\hline$\sigma_{\mathrm{R}}(\mathrm{MPa})$ & $\boldsymbol{\sigma}_{\mathrm{N}}(\mathrm{MPa})$ & $\boldsymbol{n}$ & $n / N$ \\
\hline 0.27 & 0.20 & 600,000 & 0.16 \\
\hline
\end{tabular}

For block pavement, rutting and fatigue analyses are verified.

\section{Economic Comparison}

Table 13 shows the construction and maintenance costs per unit (at construction year). The maintenance intervention programs presented for the different types of pavements comply with the maintenance plans currently adopted by the Italian port management bodies. Table 14 lists the overall construction costs of each designed pavement $[37,44]$. 
Table 13. Unit prices of construction and maintenance costs.

\begin{tabular}{ccc}
\hline Material or Work & Cost & Units \\
\hline Bituminous asphalt wearing course & 184.65 & $€ / \mathrm{m}^{3}$ \\
Bituminous asphalt binder course & 157.51 & $€ / \mathrm{m}^{3}$ \\
Bituminous asphalt base course & 140.25 & $€ / \mathrm{m}^{3}$ \\
Tack-coat & 1.11 & $€ / \mathrm{m}^{2}$ \\
Concrete for slabs & 132.12 & $€ / \mathrm{m}^{3}$ \\
Slabs placing and finishing & 11.00 & $€ / \mathrm{m}^{2}$ \\
Cement-bound base course & 40.32 & $€ / \mathrm{m}^{3}$ \\
Concrete blocks and bedding sand & 26.55 & $€ / \mathrm{m}^{3}$ \\
Lean concrete base & 40.32 & $€ / \mathrm{m}^{3}$ \\
Crushed rock base material & 24.99 & $€ / \mathrm{m}^{3}$ \\
Joint sealing & 42.00 & $€ / \mathrm{m}^{3}$ \\
8-cm depth milling of bituminous pavement & 11.10 & $€ / \mathrm{m}^{2}$ \\
Grinding of concrete pavement & 3.86 & $€ / \mathrm{m}^{2}$ \\
Taking apart and relaying of concrete blocks & 15.00 & $€ / \mathrm{m}^{2}$ \\
\hline
\end{tabular}

Table 14. Construction costs of each designed pavement.

\begin{tabular}{cc}
\hline Type of Pavement & Construction Cost $\left(\mathbf{\epsilon} / \mathbf{m}^{\mathbf{2}}\right)$ \\
\hline Asphalt pavement & 86.80 \\
Concrete pavement & 74.55 \\
Concrete block pavement & 58.52 \\
\hline
\end{tabular}

Nominal maintenance costs have been calculated according to Equation (19):

$$
C_{x}=C_{0}(1+i)^{x}
$$

where $C_{x}$ is the maintenance cost incurred in year $x ; C_{0}$ is the maintenance cost at construction year; $i$ is the annual inflation rate equal to $1.5 \%$, which is the average value of the eighteen last years in Italy; $x$ is the time in the future in years.

Discounted maintenance costs are calculated according to Equation (20):

$$
C_{A, x}=\frac{C_{x}}{(1+r)^{x}}
$$

where $C_{A, x}$ is the maintenance cost discounted at construction year $x ; r$ is the annual discount rate equal to $1.9 \%$ (the risk premium for the investment is $0.4 \%$ ).

Finally, the present value (PV) of each pavement is calculated according to Equation (21):

$$
\mathrm{PV}=\mathrm{C}_{C}+\sum_{x=1}^{N} C_{A, x}
$$

where $C_{C}$ is construction cost incurred in year 0 and $N$ is the number of years in the analysis period.

Table 15 shows the obtained PV.

Table 15. Present value of each designed pavement.

\begin{tabular}{cc}
\hline Type of Pavement & PV $\left(\mathbf{\epsilon} / \mathbf{m}^{\mathbf{2}}\right)$ \\
\hline Asphalt pavement & 106.41 \\
Concrete pavement & 79.33 \\
Block pavement & 80.39 \\
\hline
\end{tabular}


The pavement composed of cast in situ slabs was the best economic solution because the low-maintenance required in respect to the asphalt pavement, which suffers from rutting, and respect to concrete block pavement, which suffers from undermining blocks due to tangential loads transmitted by reach stackers. The results demonstrate that the analysis of maintenance procedures is crucial in the decision process because the PV could disagree with the construction costs.

In addition, it can be observed that for the concrete and block pavements the PV values are very close, and a small change in the costs and the planned maintenance activities could change the result of this analysis.

\section{Discussion and Conclusions}

In a port, the use, the load and the basic conditions of different areas seriously differ from each other. Therefore, the choice of a pavement typology derives from a careful analysis of the expected loads in order to design correctly the infrastructure. As for road pavements, technical and economic analysis should be carried out to identify the cost-effective solution.

This study focused on the analysis, design, and verification of a port pavement to be laid in an Italian terminal area trafficked by reach stackers used to move containers. Three pavement typologies have been considered: asphalt, cast in situ concrete slabs, and concrete block pavements. Empirical and analytical methods available in the literature for heavy loaded pavements and/or road pavements have been adopted to design and verify the pavement of an intermodal cargo handling plant of a medium-size port. The Asphalt Institute and the multilayer elastic theory for asphalt pavement; the PCA method and the Westergaard and Bradbury theories for concrete pavement; the Knapton theory and the multi-layer elastic theory for block pavements. Particularly, the use of two different approaches to design and verify the pavements avoided under-sizing the layers and building not correct and durable surfaces.

All the verified pavements satisfied all fatigue and rutting criteria with a large element of conservatism because the obtained results are always below the considered limits. Indeed, the most critical result is estimated for the fatigue analysis of cement-bound base course in the block pavement (i.e., $0.16<<1$ ). This condition reduces the risk of premature failure of the verified pavements, even in more severe and not expected traffic situations (e.g., overloading, cornering, or braking).

Construction and maintenance costs have been assessed for 20-year life service considering the economic and financial conditions of the recent and current Italian market. The structurally relevant solutions were quantified and compared objectively using the present value of pavement works. The cast in situ concrete pavement and the modular pavement are the least expensive options: both are about 35\% less than the asphalt pavement. The results highlight the need for technical and economic criteria to choose the best option, taking into account the strengths and weaknesses of each available solution. A port pavement designer should choose between pavement systems of low construction cost that require frequent and/or expensive maintenance and pavement systems of high construction cost but with low maintenance both in cost and frequency. Therefore, the theoretical objective of uninterrupted port operations during the pavement service life should be pursued with the LCCA approach to identify the best technical and economic option.

Author Contributions: Conceptualization, P.D.M. and G.L.; Methodology, L.M.; Software, L.M.; Validation, P.D.M., L.M. and G.L.; Formal Analysis, L.M. and P.D.M.; Investigation, G.L.; Resources, L.M.; Data Curation, L.M. and G.L.; Writing-Original Draft Preparation, L.M.; Writing-Review and Editing, P.D.M., L.M. and G.L.; Visualization, P.D.M. and G.L.; Supervision, P.D.M. and G.L.

Funding: This research received no external funding.

Conflicts of Interest: The authors declare no conflict of interest. 


\section{References}

1. Abualtayef, M.; De Heer, R.; Kuroiwa, M.; Matsubara, Y.; Seif, A. Sensitivity analysis of heavy pavement design for a container terminal area, case study: Port of Gaza, Palestine. J. Appl. Sci. 2007, 7, 1241-1248. [CrossRef]

2. Di Mascio, P.; Loprencipe, G.; Moretti, L. Criteri di scelta delle pavimentazioni portuali. In Proceedings of the 1st Italian Congress Porti\&Navigazione: Sostenibilità e Sicurezza nel Trasporto Marittimo, Rome, Italy, 23 May 2012.

3. Meletiou, M.; Knapton, J. Container terminal pavement management. In UNCTAD Monographs on Port Management; United Nations: New York, NY, USA, 1987; p. 65.

4. Razdan, A.; Dinesh, S.; Nikhil, M.; Rishil, P. Comparative study of economical analysis of different types of pavement block in pavement construction. Int. J. Sci. Technol. Eng. 2018, 4, 30-31.

5. Babashamsi, P.; Yusoff, N.I.M.; Ceylan, H.; Nor, N.G.M.; Jenatabadi, H.S. Evaluation of pavement life cycle cost analysis: Review and analysis. Int. J. Pavement Res. Technol. 2016, 9, 241-254. [CrossRef]

6. Corazza, M.V.; Di Mascio, P.; Moretti, L. Management of sidewalk maintenance to improve walking comfort for senior citizens. In WIT Transactions on the Built Environment; Brebbia, C.A., Ricci, S., Eds.; WIT Press: Southampton, UK, 2017; Volume 176, pp. 195-206.

7. Corazza, M.V.; Di Mascio, P.; Moretti, L. Managing sidewalk pavement maintenance: A case study to increase pedestrian safety. J. Traffic Transp. Eng. (Engl. Ed.) 2016, 3, 203-214. [CrossRef]

8. Zoccali, P.; Moretti, L.; Di Mascio, P.; Loprencipe, G.; D’Andrea, A.; Bonin, G.; Teltayev, B.; Caro, S. Analysis of natural stone block pavements in urban shared areas. Case Stud. Constr. Mater. 2018, 8, 498-506. [CrossRef]

9. Consiglio Nazionale delle Ricerche. Catalogo delle Pavimentazioni Stradali. In Consiglio Nazionale delle Ricerche, Bollettino Ufficiale; Terra, M., Ed.; Consiglio Nazionale delle Ricerche: Rome, Italy, 1995; Volume 178, p. 95. (In Italian)

10. Knapton, J.; Smith, D.R. The North American port pavement design manual. In Proceedings of the 3rd International Workshop on Concrete Block Paving, Cartagena de Indias, Colombia, 10-13 May 1998.

11. Bucchi, A. Tipologie delle pavimentazioni interportuali. In Proceedings of the National Congress La Ricerca nel Settore Delle Infrastrutture Interportuali e Aeroportuali, Trieste, Italy, 28-29 June 1995; Izzi, S., Ed.; FrancoAngeli s.r.l.: Milano, Italy, 1996; Volume 1. (In Italian)

12. Iskakbayev, A.; Teltayev, B.; Oliviero Rossi, C. Steady-state creep of asphalt concrete. Appl. Sci. 2017, 7, 142. [CrossRef]

13. Loprencipe, G.; Cantisani, G. Evaluation methods for improving surface geometry of concrete floors: A case study. Case Stud. Struct. Eng. 2015, 4, 14-25. [CrossRef]

14. Praticò, F.; Ammendola, R.; Moro, A. Mitigating the adverse impacts of fuel spillages on airfield pavements by improving HMA chemical resistance. In Proceedings of the 1st International Conference on Transportation Infrastructure (ICTI 2008), Beijing, China, 24-26 April 2008.

15. Cantisani, G.; D'Andrea, A.; Di Mascio, P.; Loprencipe, G. Reliance of pavement texture characteristics on mix-design and compaction process. In Proceedings of the 8th RILEM International Symposium on Testing and Characterization of Sustainable and Innovative Bituminous Materials, Ancona, Italy, 7-9 October 2015; Springer: Dordrecht, The Netherlands, 2016; pp. 271-281. [CrossRef]

16. Øverli, J. Experimental and numerical investigation of slabs on ground subjected to concentrated loads. Open Eng. 2014, 4, 210-225. [CrossRef]

17. Assoporti. Movimenti in principali porti italiani-anno 2015. Available online: http://www.assoporti.it/ media/2712/movimenti_portuali_-2015_19mar18.pdf (accessed on 16 February 2019).

18. Miccoli, S.; Finucci, F.; Murro, R. Assessing project quality: A multidimensional approach. Adv. Mater. Res. 2014, 1030, 2519-2520. [CrossRef]

19. Miccoli, S.; Finucci, F.; Murro, R. Criteria and procedures for regional environmental regeneration: A European strategic project. Appl. Mech. Mater. 2014, 675-677, 401-405. [CrossRef]

20. Knapton, J.; Nixon, N. The Structural Design of Heavy Duty Pavements for Ports and Other Industries, Enlarged ed.; British Port Association: London, UK, 1983.

21. Knapton, J. The Structural Design of Heavy Duty Pavements for Ports and Other Industries, 4th ed.; Taylor \& Francis: Abingdon, UK, 2007. 
22. Asphalt Institute. Thickness Design. Asphalt Pavements for Heavy Wheel Loads, 1st ed.; Asphalt Institute: College Park, MD, USA, 1986.

23. Asphalt Institute. Asphalt Pavement Thickness Design Software for Highways, Airports, Heavy Wheel Loads and Other Applications; Asphalt Institute: College Park, MD, USA, 2005.

24. Huang, Y.H. Pavement Analysis and Design, 2nd ed.; Prentice Hall: Upper Saddle River, NJ, USA, 2004.

25. Ministero de fomiento. Guidelines for Design and Construction of Port Pavement; Ministero de fomiento: Madrid, Spain, 1994.

26. ANAS. Elenco Prezzi Nuove Costruzioni e Manutenzione Straordinaria; Ente nazionale per le strade: Rome, Italy, 2018. (In Italian)

27. Domenichini, L.; Di Mascio, P. Indagine sulle Condizioni Climatiche Italiane ai fini del Dimensionamento delle Sovrastrutture Stradali; DISAT 91/3; Università degli Studi dell'Aquila: L'Aquila, Italy, 1991. (In Italian)

28. AASHTO. AASHTO Guide for Design of Pavement Structures; American Association of State Highway and Transportation Officials: Washington, DC, USA, 1993.

29. PCA. Structural Design for Roller-Compacted Concrete for Industrial Pavements; Portland Cement Association: Skokie, IL, USA, 1987.

30. Westergaard, H.M. Stresses in concrete pavements computed by theoretical analysis. Public Roads 1926, 7, 25-35.

31. Bradbury, R.D. Reinforced Concrete Pavements; Wire Reinforcement Institute: Washington, DC, USA, 1938.

32. ANAS. Elenco Prezzi Costi Elementari; Ente nazionale per le strade: Rome, Italy, 2017. (In Italian)

33. Jung, Y.; Freenman, T.J.; Zollinger, D.G. Guidelines for Routine Maintenance of Concrete Pavement; Federal Highway Administration: Austin, TX, USA, 2008.

34. Nebraska Department of Roads. Pavement Maintenance Manual; Nebraska Department of Roads: Lincoln, NE, USA, 2002.

35. Gedafa, D.S. Performance prediction and maintenance of flexible pavement. In Proceedings of the 2007 Mid-Continent Transportation Research Symposium, Ames, IA, USA, 16-17 August 2007.

36. ANAS. Elenco Prezzi Manutenzione Ordinaria; Ente nazionale per le strade: Rome, Italy, 2017. (In Italian)

37. Moretti, L.; Cantisani, G.; Di Mascio, P. Management of road tunnels: Construction, maintenance and lighting costs. Tunn. Undergr. Space Technol. 2016, 51, 84-89. [CrossRef]

38. ISTAT. Le prospettive per l'economia italiana nel 2015-2017; Istituto Nazionale di Statistica: Rome, Italy, 2018. (In Italian)

39. International Monetary Fund. World Economic Outlook: Subdued Demand: Symptoms and Remedies; IMF: Washington, DC, USA, 2016.

40. PricewaterhouseCoopers. The World in 2050. The Long View. How Will the Global Economic Order Change by 2050? PWC: London, UK, 2017.

41. De Jong, D.L.; Peatz, M.G.F.; Korswagen, A.R. Computer Program BISAR, Layered Systems under Normal and Tangential Surface Loads; Shell Laboratorium Amsterdam: Amsterdam, The Netherlands, 1973.

42. Miner, M.A. Cumulative damage in fatigue. J. Appl. Mech. 1945, 67, A159-A164.

43. Ferrari, P.; Giannini, F. Ingegneria Stradale, vol. II Corpo Stradale e Pavimentazioni; ISEDI: Torino, Italy, 2007. (In Italian)

44. Moretti, L. Technical and economic sustainability of concrete pavements. Mod. Appl. Sci. 2014, 8, 1-9. [CrossRef]

(C) 2019 by the authors. Licensee MDPI, Basel, Switzerland. This article is an open access article distributed under the terms and conditions of the Creative Commons Attribution (CC BY) license (http:/ / creativecommons.org/licenses/by/4.0/). 